\title{
Sorting Tests of Unsorted Municipal Solid Waste from Germany for a Selected Opto-Pneumatic Sorting Machine
}

\author{
Wojciech Hryb* \\ Department of Technology and Installations for Waste Management, \\ Faculty of Energy and Environmental Engineering, Silesian University of Technology \\ Konarskiego 18, Gliwice 44-100, Poland \\ Received: 17 March 2014 \\ Accepted: 8 July 2014
}

\begin{abstract}
Polish waste management systems currently are under development and modernization in order to adjust to European Union standards. Mechanical biological waste treatment systems installed in so-called regional municipal solid waste treatment plants are being developed. This type of plant needs to be operated in order to obtain required levels of recycling and waste recovery and to limit the amount of biodegradable waste directed to landfills. A key element of all these type of devices are sorting plants. This paper presents the results of sorting tests of unsorted municipal solid waste from Koblenz city. Tests were performed in the Research and Test Facility located at TITECH GmbH in Mülheim-Kärlich in Germany. The tests made it possible to determine efficiency of the process of automatic separation of plastics and papers using a Titech autosort separator equipped with near infra-red sensor (NIR 1). Test results show differences in the morphological composition of unsorted municipal solid waste from Poland and Germany, and their potential in respect to content of recovered materials.
\end{abstract}

Keywords: sorting tests, separation, efficiency, recovery index, opto-pneumatic sorting machine, unsorted municipal solid waste

\section{Introduction}

Sorting plants should be adjusted to be able to receive unsorted municipal solid wastes as well as selectively collected waste that is only going to increase in amount in the next couple of years.

Proper organization of the mechanical waste treatment process, with sorting and selection of appropriate devices, has a crucial influence on the efficiency of this process.

Most Polish sorting plants do not meet strict requirements which will enter in force on 01.01.2016 and which

*e-mail: wojciech.hryb@polsl.pl arise from the order concerning criteria and procedures allowing disposal of waste in a particular landfill by [1] (Journal of Laws 2013 item 38) and which refer to the remains after mechanical waste treatment. This is confirmed by tests of subscreen fraction (graining 0-40 mm) and ballast fraction from a typical sorting plant for mixed wastes in Poland [2].

Due to the above, it is necessary to modernize sorting stations of old type and increase levels of recovery of particular pieces of material as well as production of highquality alternative fuels that could have a positive influence on plant finances and which will decrease the amount of waste qualified into ballast coming from this type of device. 
In Polish waste sorting plants both in the modernized ones and in newly constructed plants many types of devices are used for classification of wastes. These are screens, air separators, metal separators, and more often opto-pneumatic separators.

Opto-pneumatic separators may be widely applied depending on the sensors used, i.e. NIR - near infra-red, VIS - visibility sensor, XRF spectrometer - an X-ray instrument used for routine, relatively non-destructive chemical analyses, and special processing techniques and sorting wastes based on proper atomic densities.

Wastes are transported through the sensor zone located over the conveyor belt. Sensors identify material properties such as structure, shape, color, spectrum, density, etc. required to identify a given material. Pieces of materials with preliminarily determined properties are pneumatically separated at the end of the conveyor belt through a set of nozzles.

Such separators are used not only to separate many types of plastics and paper or to clean organic fractions, but they are also applied for natural raw materials, and recycling of glass, timber, or other materials as presented in publications [3-8].

An advantage of the use of opto-pneumatic sorters in sorting plants, apart from wide possibilities of their application, is an ability to obtain high throughput which, considering the increasing stream of selectively collected wastes, can contribute to the wider use of these devices.

An automatic sorting separator for given fractions of material generally consists of a sensor (scanner) with a system of special lamps and a computer, a nozzle board, fixtures, and a compressed air regulator. Moreover, the system includes a fast-scanning conveyor with supportive structure for the sensor, separation chamber, compressor for a given system or one compressor station for all the systems with compressed air supply and fitting system. Wastes should be delivered to the separator through the conveyor or a set of conveyors with the necessary transfer stations that assure equal and single layer distribution of wastes on the fast scanning conveyor belt in order to avoid overlaying of particular particles of wastes.

Width of the conveyor belt and the capacity of the separator must be adjusted to the amount of segregated wastes. Active width of the conveyor belt should be adjusted to the width of sensor detection. Sensor should be incorporated on the supportive structure over fast-scanning conveyor belt.

The separation chamber should consist of a compartment with a roll that can be set to the appropriate type of material layout - shifted and set vertically or horizontally. Shifting range of the compartment is adjusted to the material and enables optimal sorting at least $\pm 100 \mathrm{~mm}$ from the nominal layout. It should also have a regulated structure that eliminates uncontrolled reflexes of the secreted materials and incorrect disposal of material (ex. mixing raw material with ballast) [9].

It should be noted that in order to apply an automatic sorting system for the separation of unsorted municipal solid waste, stream of wastes should first undergo preparatory processes. These include: tearing bags, separating large waste in an initial sorting cabin (large pieces of foil and cartoons, which can cause overlapping objects), separating mineral and organic fractions, and equal spreading of wastes on the belt on its whole width with the use of a fast-scanning conveyor belt. Applying all these procedures assures effective opto-pneumatic sorting of unsorted municipal solid wastes. However, the human factor cannot be completely eliminated. If the system identifies PET, and near a PET bottle for example a piece of paper can be found, it will be disposed into the PET fraction by the compressed air and will form its pollution, unless it is removed manually.

Summing up the main advantages of the application of opto-penumatic sorters, it is the high capacity of the technological line maintaining high efficiency of secretion of recovered materials that allows for recovery of over $80 \%$ of material fractions while employing only a couple of persons for additional cleaning of separated material fractions. It gives positive financial results to the plant and decreases the amount of ballast disposed of in the landfill. Due to applied automatic processes, it also limits employment.

The disadvantages include high costs of investment, lack of possibility to identify glass and black packaging (they do not reflect light but absorb it), and difficulties separating long, heavy objects, and large materials.

Possible applications of the TITECH autosort system are given below [10]:

- Polymer sorting - sorting of e. g. beverage cartons, PE, PP, PS, PVC, PET, EPS, ABS by type of material

- Mixed-paper removal - removing paper from a mixed input stream

- RDF production - producing an RDF fraction

- RDF plus - producing an RDF fraction, with additional stone/timber distinction

- CND sorting - organic/non-organic sorting

- $\quad$ PET/PE sorting - sorting of PET/PE by color, e.g. light blue, clear, etc.

- Wood cleaning - producing a clean timber/chipboard fraction by removing painted and coated wood

- Paper Plus - producing a clean unstained fraction

- Metal removal - removing all metals

- Multi functional - separate up to five packages in one application

- Special applications - on request

The sensor most widely used in opto-pneumatic separators in the waste management industry is the NIR (near infrared spectroscopy) sensor. NIR also is used in different sorts of devices, e.g. for the analysis of soil, litter, and plantderived materials [11].

\section{Experimental Procedures}

Tests were performed on 10 November 2011 in the Research and Test Facility of TITECH GmbH in MülheimKärlich in Germany. The trip was partially financed by Titech Company and the remaining costs were covered by Project BK-298 (RIE-3) 2011 "Tests of operational efficiency of a selected waste sorting plant." The selected testing system applied during tests is presented in Table 1. 
Table 1 . The sorting system characteristics used during the tests [10].

\begin{tabular}{|c|c|c|}
\hline No. & Name & Test system parameters \\
\hline 1 & Detection Unit & TITECH autosort \\
\hline 2 & Working width & $1000 \mathrm{~mm}$ \\
\hline 3 & Sensor & NIR1 \\
\hline 4 & Resolution & Standard \\
\hline 5 & Valves & $\begin{array}{r}36 / 16.5 \text { Extra High Power (valves } \\
\text { block used during the test } 1 \text { ) }\end{array}$ \\
\cline { 3 - 3 } 5 & $\begin{array}{r}36 / 30 \text { High Power (valves block used } \\
\text { during the test 2) }\end{array}$ \\
\hline 6 & Belt speed & $3 \mathrm{~m} / \mathrm{s}$ \\
\hline 7 & Air pressure & 6 bar \\
\hline
\end{tabular}

During tests two samples of unsorted municipal solid wastes from Koblenz city in Germany were tested. First sample with weight of $147 \mathrm{~kg}$ and the second of $220 \mathrm{~kg}$ were input from a big bag to the conveyor belt of tested sorting line equipped with opto-pneumatic sorter Titech autosort. The moment of sample delivery to the conveyor belt and a view of Titech autosort separator with separation chamber is presented in Fig. 1.

Then the waste was transported through a set of conveyor belts, including the fast scanning conveyor belt (even spreading of the particles of wastes on the belt) into the operation zone of the opto-pneumatic separator. The sorter was set to separate plastic fraction (polymers) and paper. Once the system identifies plastic and paper on the conveyor belt a signal is transmitted to start nozzles with compressed air, which blow given material in the separation chamber onto another conveyor belt, having it separated from other waste. During sorting tests of the first sample a set of 36/16.5 extra high power valves were applied, where distance between compressed air nozzles was $16.5 \mathrm{~mm}$. During tests of the second sample a set of $36 / 30$ high power valves were used with the distances between the nozzles with compressed air of $30 \mathrm{~mm}$. Wastes separated in the sep- aration chamber were propelled onto conveyor belts. From there they were sent to large bags and subsequently to sorting tables, where they were manually separated into various material fractions. Afterward they were weighed on a platform electronic scale. If it was difficult to identify the type of plastic due to lack of marking, a manual NIR analyzer was used for identification. Fig. 2 presents manual segregation into groups of materials in fractions previously separated by an opto-pneumatic separator, residues, and manual NIR analyzer.

Results of the performed analysis are presented in Table 2 (for the first test) and in Table 3 (for the second test).

Content analysis of the separated fraction and ballast made it possible to determine efficiency of the process and define recovery index (sorting ability) of polymers and paper.

Within the wastes of particular material fractions separated during manual separation a group of multi material waste (composites) was separated, which consisted mainly of foil bags with content. The system identifies that waste as polymer with no consideration to the content of the bag. Often, due to the bag's large mass the nozzles are not able to blow it into separate polymer fraction. In actual sorting plants for unsorted municipal solid waste this problem is solved by the use of a bag breaker. Another fraction that needs to be discussed is a fraction named "residues fraction," which contains waste of graining below $80 \mathrm{~mm}$, i.e. this is a fraction difficult for manual segregation. It should be underlined that small pieces of plastic and paper dominated in this fraction. Kitchen waste share was slight due to the effective system of its collection at the source.

Natural textiles, (i.e. cotton) were identified by the system as paper, whereas synthetic textiles were considered as polymer.

\section{Results and Discussion}

Sorting test procedure and results are presented in Tables 2 and 3, and on the basis of the results it achieved recovery indexes that were calculated for the analyzed system.

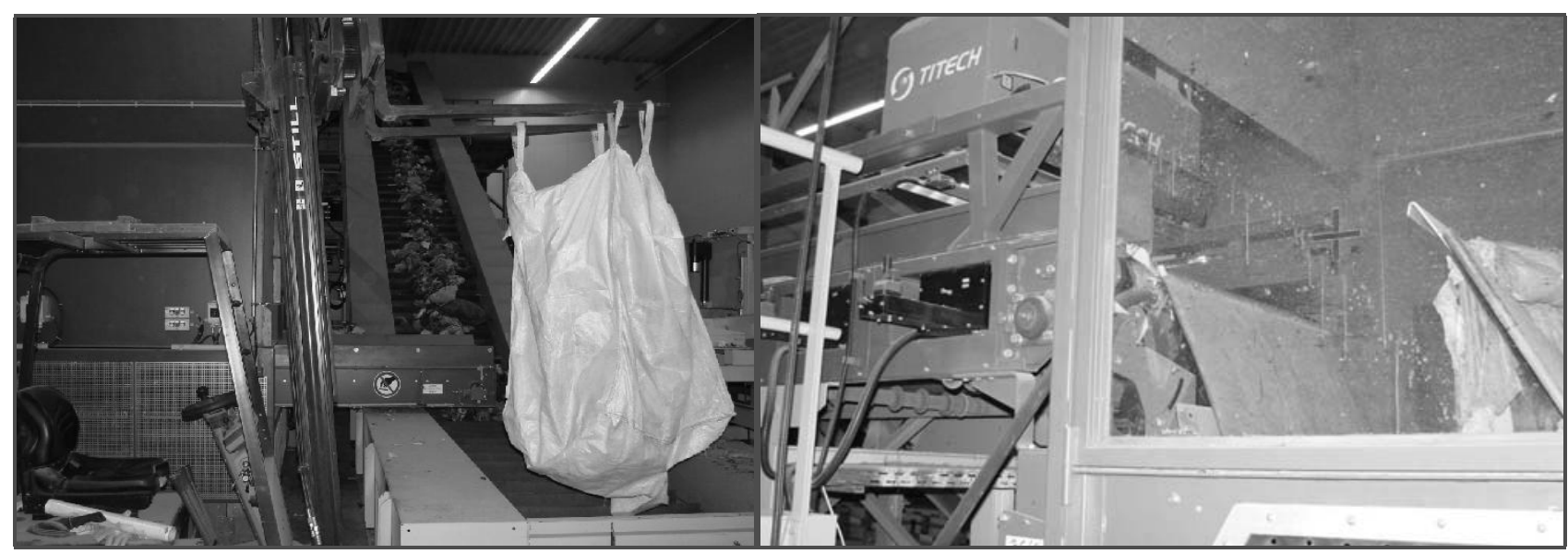

Fig. 1. Input material (on the left) and Titech autosort separator - the view of scanner and separation chamber (right photo by W. Hryb). 
On the basis of the test results presented in Tables 2 and 3 and formula (1) for the efficiency of separation of particular fractions, the so-called recovery index (sorting ability), the ability to separate polymers and paper for a given sorting system may be calculated.

$$
W_{x}=\frac{M_{f x w}}{M_{f x w}+M_{f x b}} \times 100 \%
$$

...where:

$W_{x} \quad$ - recovery index (sorting ability) of fraction $x$ from waste, expressed in \%

$M_{f x w} \quad$ - the mass of fraction $x$ separated in the sorting line $M_{f x b} \quad$ - the mass of fraction $x$ identified in the ballast

Efficiency to separate polymers (plastics) and paper for the first test of unsorted municipal solid wastes equals:

$$
W_{\text {polymers } 1}=\frac{21.88}{21.88+2.93} \times 100 \%=88.2 \%
$$

and for paper:

$$
W_{\text {paper } 1}=\frac{5.07}{5.07+0} \times 100 \%=100 \%
$$

Whereas efficiency of polymers (plastics) and paper for the second test of unsorted municipal solid wastes equals:

$$
W_{\text {polymers } 2}=\frac{22.17}{22.17+4.5} \times 100 \%=83.1 \%
$$

and for paper:

$$
W_{\text {paper } 2}=\frac{2.39}{2.39+0} \times 100 \%=100 \%
$$

High efficiency to separate paper and plastic fractions using this type of device were confirmed in the another actual sorting plant for the unsorted municipal solid waste as presented in [12].
Optical TITECH autosort separator assures high effectiveness in separation of a given material's fraction of over $80-90 \%$. In this system the amount of paper, plastic, or metal in the ballast disposed of in the landfill falls significantly below $10 \%$ in the stream of municipal solid waste. Optical separators provide an automatic process and very high throughput and output of separated material. Persons in sorting cabins control the stream quality and if it is necessary sort out automatically separated material fractions [13].

Efficiency and reliability of opto-pneumatic sorters was also confirmed in $[14,15]$.

Morphological content of samples of unsorted municipal solid wastes from Koblenz city significantly differs from average morphological content of municipal solid wastes in large cities in Poland. The developed system of selective collection of wastes and high commitment to this system of Koblenz city community resulted in lack of glass in samples taken in the carried tests. Plastics were represented mainly by foil. The content of paper and kitchen wastes was on a very low level.

Establishment of a waste management system in Germany based on selective collection started in the 1970s. Since 1991 the oldest formalized management system for packaging waste in Europe has been operating there. In Germany, over 2.6 M tons of plastic packaging alone are consumed, and the recycling level reaches approximately $75 \%$. A system of selective collection in not obligatory for all inhabitants. Whoever wants to sort, sorts. However, everyone has to take into account a high fee for the reception of mixed wastes. The system of selective collecting was unified for all Germany as early as 20 years ago.

Inhabitants are constantly informed and educated at local and regional levels. Organizations that deal with recovery sponsor informative actions. In Germany, a deposit-refund system has been incorporated for PE bottles, aluminium cans, and reusable plastic packaging in boxes.

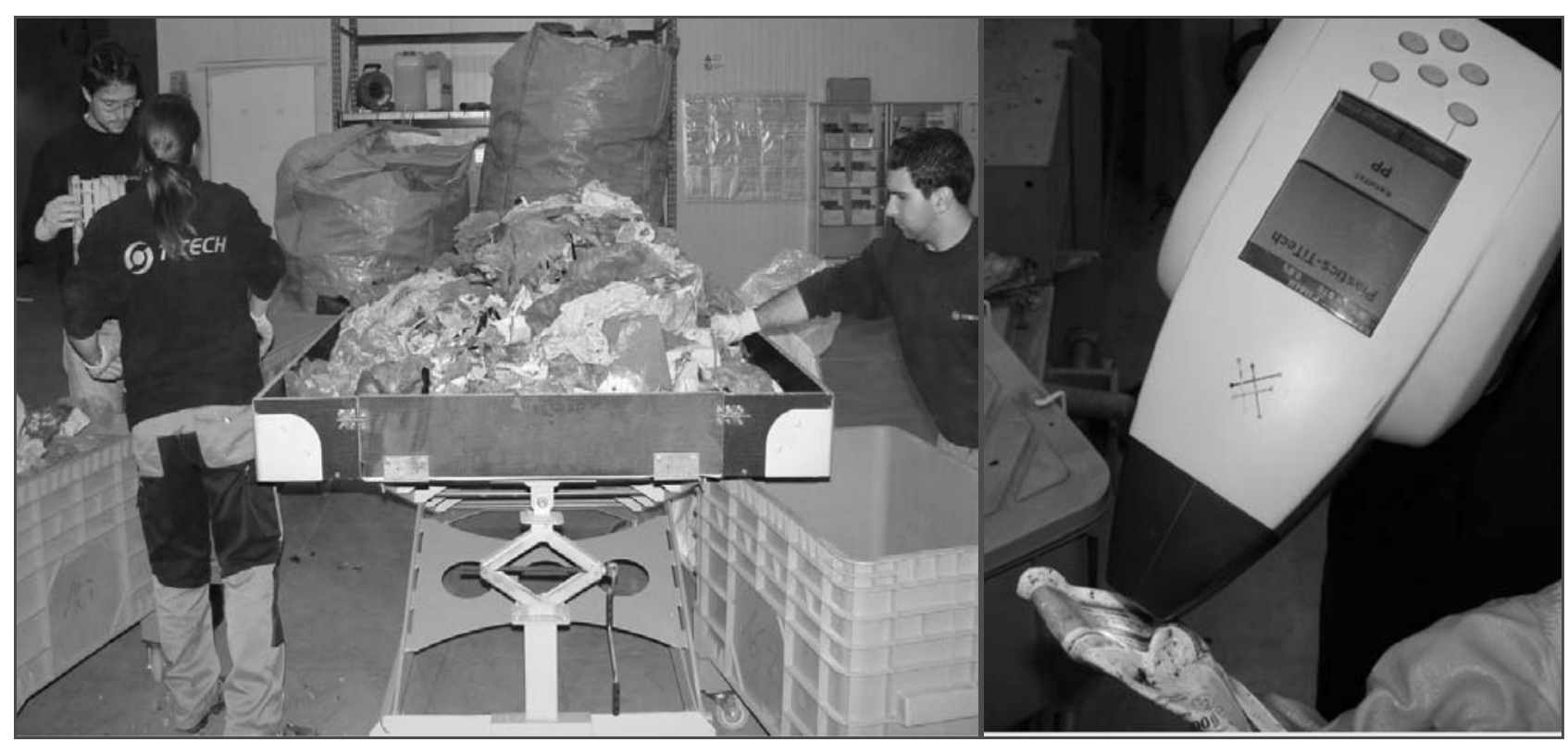

Fig. 2. Left - Manual segregation of fraction separated by the separator. Right - detection of the type of plastic by manual NIR analyzer (photo by W. Hryb). 
Table 2. Results obtained in test No. 1.

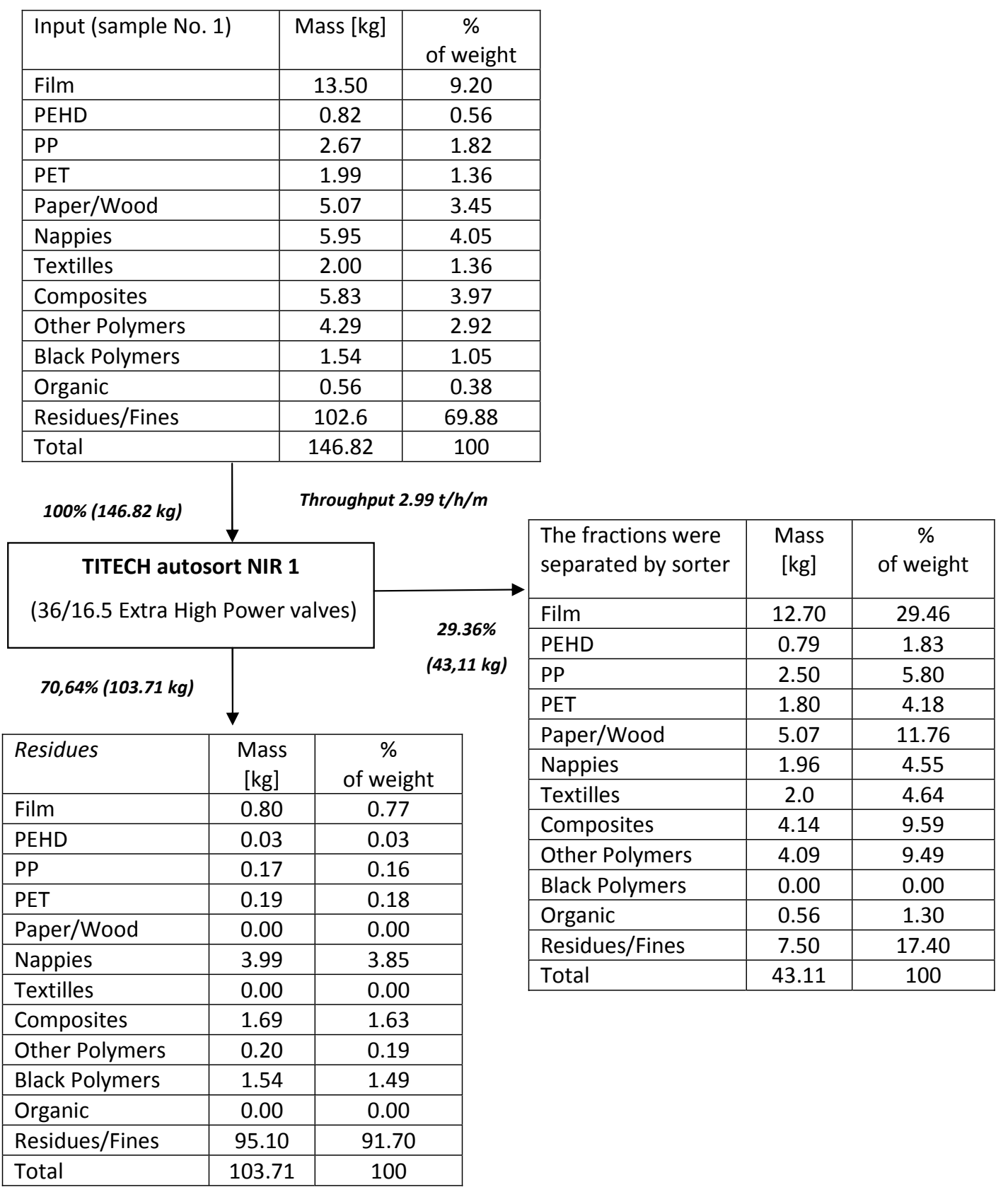

German analyses prove that introducing competition into the market resulted in a significant decrease of costs of recycling. Moreover, establishment of the deposit-refund system changed the form of collection of some packaging that was previously put into containers for selective collection [16].

In Poland, a level of selectively collected waste still does not exceed $10 \%$ of total mass of produced municipal wastes. Due to the fact that by 2020 , not less than $50 \%$ of the mass of basic materials from wastes should be reused or recycled, a dynamic development of selective collection of wastes needs to be initiated and the amount of materials gathered in this way must be multiplied [17].

Due to the above, in Poland a potential of secondary materials in the mixed municipal wastes is higher than in
Germany. Therefore, sorting is more justified and profitable, as it is possible to obtain raw materials that can be sold to recyclers.

\section{Conclusions}

Performed tests of automatic sorting of unsorted municipal solid wastes with the use of opto-pneumatic Titech sorter equipped with NIR sensor showed high efficiency in separating polymer and paper fractions. Sorting efficiency for polymer fraction amounted to $88 \%$ with the use a set of 36/16.5 extra high power valves and $83 \%$ with the use a set of $36 / 30$ high power valves. Valves spread every $16.5 \mathrm{~mm}$ give a stronger stream of compressed air, 
Table 3. Results obtained in test No. 2.

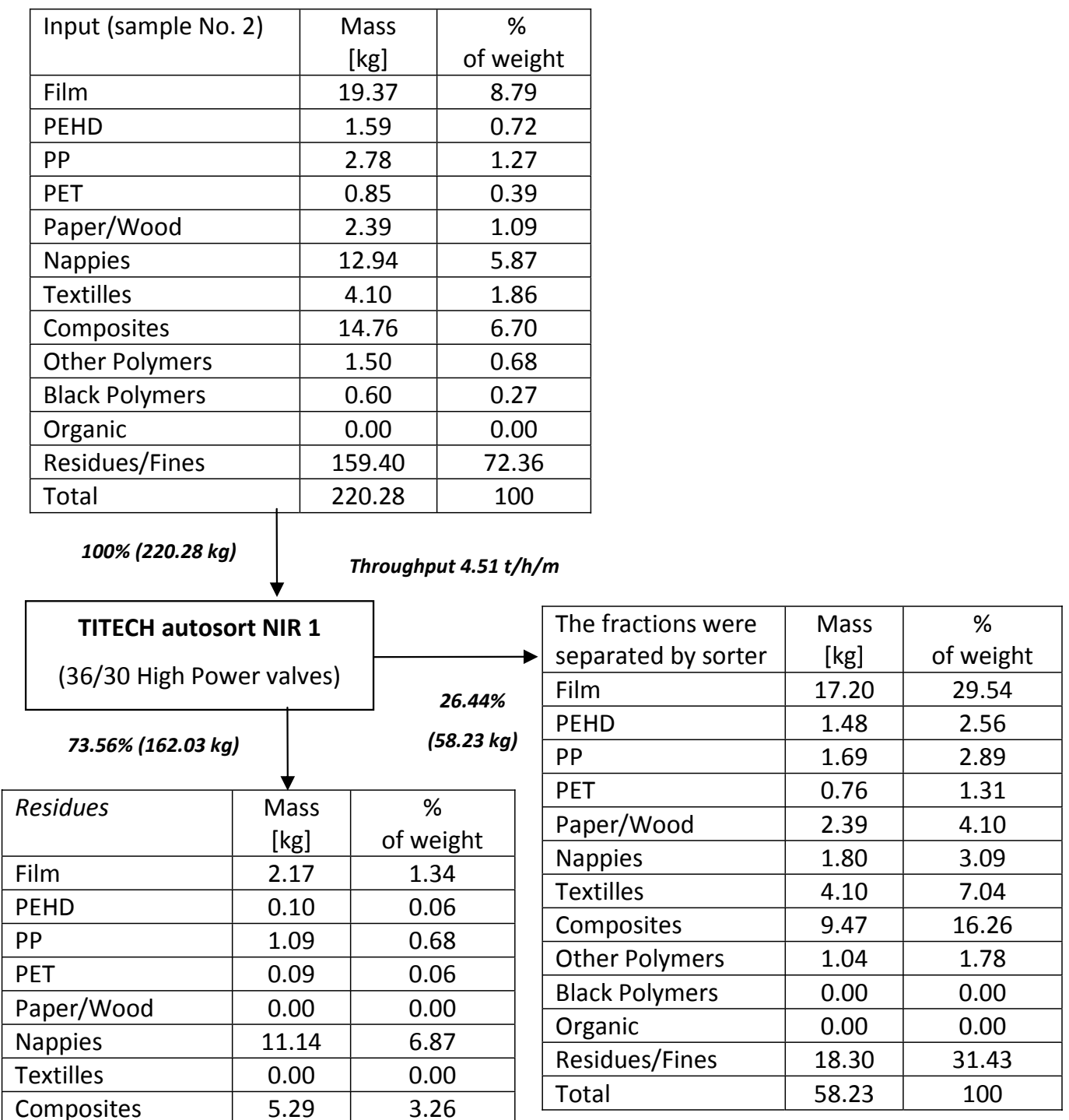

which allows directing heavier elements away to a particular fraction section. This can explain why the higher recovery index was achieved when a set of 36/16.5 extra high power valves was used. Efficiency of paper recovery for the first and second cases reached $100 \%$, and spacing of nozzles with compressed air had no influence on the result. In the tested samples paper appeared as single sheets and newspapers. It did not contain any books, for which a set of $36 / 30$ high power valves could turn out to be too weak to "shift" the fraction into the proper conveyor belt.

It needs to be considered that on the actual installation the efficiency depends on a number of operating parameters of the sorter and its fixtures and on the initial preparation of unsorted municipal solid waste (breaking bags, screening undesirable fractions, etc.). Morphological content of unsorted municipal solid wastes in Poland differs from the one in Germany. In Germany unsorted municipal solid wastes contains less recovered materials, which results from a developed system of selective collection of wastes and society's engagement in it.

\section{References}

1. Order of the Minister of Economy dated Jan 8, 2013 concerning criteria and procedures for accepting wastes to be disposed of at landfills of wastes of particular type. Journal of Laws 2013 item 38.

2. HRYB W. Properties of the Residues of Mechanical Treatment of Wastes in a Sorting Plant in the Light of Binding Legal Regulations. Pol. J. Environ. Stud. 21, (5A), 117, 2012. 
3. PASCOE R.D., UDOUDO O.B., GLASS H.J. Efficiency of automated sorter performance based on particle proximity information. Minerals Engineering 23, 806, 2010.

4. BONIFAZI G.,SERRANTI S. Imaging spectroscopy based strategies for ceramic glass contaminants removal in glass recycling. Waste Manage. 26, 627, 2006.

5. SAFAVI S.M., MASOUMI H., MIRIAN S.S., TABRIZCHI M. Sorting of polypropylene resins by color in MSW using visible reflectance spectroscopy. Waste Manage. 30, 2216, 2010.

6. RASEM HASAN A., SOLO-GABRIELE H., TOWNSEND T. Online sorting of recovered wood waste by automated XRF-technology: Part II. Sorting efficiencies. Waste Manage. 31, 695, 2011.

7. BEZATIA F., FROELICHA D., MASSARDIEB V., MARISA E. Addition of X-ray fluorescent tracers into polymers, new technology for automatic sorting of plastics: Proposal for selecting some relevant tracers. Resources, Conservation and Recycling 55, 1214, 2011.

8. LOPEZA M., SOLIVAA M., MARTINEZ-FARREA F. X., FERNANDEZB M., HURETA-PUJOLA O. Evaluation of MSW organic fraction for composting: Separate collection or mechanical sorting. Resources, Conservation and Recycling. 54, (4), 222, 2010.

9. CHEŁKOWSKI M., JAŹWIEC M., GRYGLAK M. Functional and Utilitriam Program - Construction of a complex system of waste management for Bielsko-Biała and communes in Bielski Province - Waste Management Plant S.A. 2009 [In Polish].

10. SAMA V. Titech-Test Report-Koblenz, Internal test, Sorting out polymers and paper from municipal solid waste. Mülheim-Kärlich, 10. 11. 2011.

11. CHODAK M. Review Application of Near Infrared Spectroscopy for Analysis of Soils, Litter and Plant Materials. Pol. J. Environ. Stud. 17, (5), 631, 2008.

12. HRYB W. Modernization of waste management plants exemplified by installation in Gorzów Wielkopolski. ed. by Helion Archives of Waste Management and Environemental Protection 15, (1), 47, 2013 [In Polish].

13. RAJCA M. Recovery of fractions for recycling and production of alternative fuels. Market and technical technological conditions. TOMRA Sorting Sp. z o.o., XXIV International Seminary of Waste Management - New legal Regulations, 6-9 March 2013 [In Polish].

14. Prepared by: 4R Sustainability, Inc. Portland, OR 97203; www.4RSustainability.com "Demingling the mix: An assessment of commercially available automated sorting technology" - This research project was funded by the American Chemistry Council; Second Edition January 2011.

15. A Review of Automated Technology to Sort Plastics and Other Containers, Environment and Plastics Industry Council (EPIC) and Corporations Supporting Recycling (CSR); (http://www.cpia.ca); May 2005.

16. TYCZKOWSKI J. Every country has its customs. Special journal of Recycling magazine, editorial Abrys Sp. z o.o http://e-czytelnia.abrys.pl/index.php?mod=tekst\&id=16346, No. 5/2013 [In Polish].

17. BOER E. Selective collecting wastes in communes - profit or costs only? Recycling, editorial Abrys Sp. z o.o, No. 10/2013 (154) [In Polish]. 
